\title{
A review on corona virus pandemic: Update on epidemiology, diagnosis, and treatment
}

Mishal Rani ${ }^{1}$, Muhammad Farooq ${ }^{1}$, Sania Aamir ${ }^{1}$, Iqra Mir ${ }^{1}$, Muhammad Hassan $^{1}$, Bakhtiar Ahmed ${ }^{1}$, Abeera Iftikhar ${ }^{1}$, Syed Rizwan Hussain Shah ${ }^{1}$, Shazia Rafique ${ }^{1}$, Samia Afzal ${ }^{1}$, Muhammad Idrees ${ }^{1}$, Iram Amin ${ }^{1}$ and Muhammad Shahid ${ }^{1 *}$

1. Division of Molecular Virology, National Centre of Excellence in Molecular Biology (CEMB), University of the Punjab, Lahore, Pakistan

*Corresponding author's email:shahidimran@cemb.edu.pk

\section{Citation}

Mishal Rani, Muhammad Farooq, SaniaAamir, Iqra Mir, Muhammad Hassan, Bakhtiar Ahmed, AbeeraIftikhar, Syed RizwanHussain Shah, Shazia Rafique, Samia Afzal, Muhammad Idrees, Iram Amin and Muhammad Shahid. A review on corona virus pandemic: Update on epidemiology, diagnosis, and treatment. Pure and Applied Biology.Vol. 11, Issue 1, pp146-158. http://dx.doi.org/10.19045/bspab.2022.110016

\begin{tabular}{llll}
\hline \hline Received: 00/02/2021 & Revised: 00/04/2021 & Accepted: 00/05/2021 & Online First: 21/05/2021 \\
\hline
\end{tabular}

\section{Abstract}

Coronavirus, at present, has created major health havoc across the world. It has been declared as a global health threat by the World Health Organization (WHO). The world has already experienced major outbreaks of coronaviruses previously. A few of the major outbreaks from the past include Severe acute respiratory syndrome coronavirus (SARS-CoV) in 2002, Middle East Respiratory Syndrome (MERS-CoV) in 2012, and the present Severe acute respiratory syndrome coronavirus 2(SARS-CoV-20). All of these belonged to Coronaviridae and have been known to cause respiratory infections mostly. The infection ranges from mild to severe and even death with common symptoms of fever, chills, shortness of breath, gastrointestinal problems, etc. This respective review article discusses the prominent members of Coronaviridae in detail. It highlights the major outbreaks of coronaviruses faced by the world and the substantial mortalities caused by them. It also talks about the most effectively used methods of diagnosis for such viruses andenumerates the antivirals and drug combinations found effective against the past and present coronavirus infections. Coronavirus is at present the hottest topic for study due to COVID-19. This review article aims to collectively present all the relevant data for our readers which can help them to strengthen their basic knowledge for future studies.

Keywords: Coronavirus; COVID-19; Diagnosis; MERS-CoV; MERS outbreak; SARS-CoV; SARS outbreak;Symptoms;Treatment; Vaccination

\section{Introduction}

Coronaviruses are non-segmented, enveloped viruses with a positive-sense, single-stranded RNA as the genome. According to their taxonomic classification, they belong to theCoronaviridae family; order Nidovirales, and kingdom Riboviria. They are commonly known to cause diseases in humans and other mammals including birds [1, 2]. There are four genera of 
coronavirus including alpha-coronavirus, beta-coronavirus, gamma-coronavirus and delta-coronavirus. The infection range of coronaviruses lies between mild illnesses like common cold to lethal cases of Severe acute respiratory syndrome coronavirus (SARS$\mathrm{CoV}), \quad$ Middle East Respiratory Syndrome (MERS-CoV), and the present Severe acute respiratory syndrome coronavirus 2(SARS-CoV-2).

Being one of the largest groups of RNA viruses, the size of the genome of coronaviruses is about 26-32 kbps [3, 4]. They were first discovered, causing infection in domesticated chickens, during the 1930s with a mortality rate ranging between 40$90 \%$. Later, in the1960s human coronaviruses were discovered.

Talking about the structural features of the virus, it is mostly spherical with certain surface projections and an average diameter of $125 \mathrm{~nm}$ [5]. These viruses are normally enveloped with a lipid bilayer having the spikes and structural proteins anchored within. A nucleocapsid is enclosed within the envelope. All of these structural features are crucial for virus protection outside the host [6]. The RNA genome of the virus is complexed with nucleocapsid protein giving it a helical shape within the viral membrane containing three viral proteins called the spike (S), the membrane (M), and a small protein (E). The spike is a peplomer-forming surface glycoprotein that imparts a crownlike morphology to the virus due to which it is popularly known as "corona" [7]. Some coronaviruses are reported with an additional protein named hemagglutinin esterase (HE). It is thought to aid viral entry and its in vivo pathogenesis. However, SARS-CoV doesn't encode for HE [8].

The replication cycle of the virus occurs inside the body of thehost via a 4 step process including attachment and entry through viral spikes, replication through RNA-dependentRNA-polymerase, and finally the release of the progeny virions by exocytosis of secretory vesicles [4]. All of the proteins of coronaviruses are reportedly important for their pathogenesis or disease development. The main target area of these viruses is the respiratory system of the host which leads to severe syndromes as well. The infected individuals can transmit viruses to the environment and people living around them. People can catch the virus if close contact with infected individuals. The viruses can spread through cough, sneezes, fecal-oral route, etc.

\section{Outbreaks}

Coronaviruses are commonly associated with respiratory tract infections and syndromes. Their three popular human outbreaks include the SARS outbreak in 2002, the MERS outbreak in 2012, and the presentSARSCoV-2also known as Coronavirus Disease 2019 (COVID-19) outbreak. However, history is flooded with several other pandemic stories of these viruses as well.

In the late 1960s, viruses belonging to this family were found to affect the human respiratory tract, central nervous system, and enteric system, these were called Human Coronaviruses (HCoVs). Two strains $\mathrm{HCoV}-$ 229E and HCoV-OC43 were common [9]. Coronaviruses represented as $\mathrm{CoVs}$ includeviruses that can transmit between species. It was in 2002 that 792 people got affected bya viral infection and 31 persons died in Guangdong province. Similar reports of severe respiratory diseases were reported in different countries including Canada, Hong Kong, and Vietnam where many health care workers acquired the disease too. In March 2003, the disease was generally named SARS. Global efforts were done to control the virus spread and to understand the viral infection and its pathogenesis. A Chinesehealthcare worker who arrived in Hong Kong was considered as a carrier of the virus and cause of its possible transmission in Hong Kong as he died showing symptoms of 
SARS in the hospital. Many countries including Canada, United States, Thailand, Vietnam, Taiwan, and Singapore collaborated with CDC to investigate and research it. SARS had spread globally and affected Asian, European, and American countries very much [10]. The main reservoirs for SARS-CoV were bats and the intermediate host was carnivorous [11].

In mid-2002, there were three outbreaks of $\mathrm{HCoV}-\mathrm{OC} 43$ strain reported in geographically distant health care facilities in Australia. This strain had caused severe respiratory diseases. These outbreaks signified the importance of studying coronavirus infection as this strain had caused notable diseases in aged people [12].

Two strains of coronavirus HCoV-NL63 and CoV-HKU1 were discovered in the Netherlands and China respectively, during 2004 [13, 14]. A few-months-old child showing symptoms of fever and inflammation of lungs and conjunctiva was hospitalized in March 2004, the scientist isolated HCoV-NL63 strain from the nasopharyngeal aspirate. This novel coronavirus strain was placed in group 1 and distributed worldwide. From 2000 to 2003, 11 positive samples of $\mathrm{HCoV}-\mathrm{NL} 63$ were detected [9].

The HCoV-NL63 caused severe respiratory disease in both children and adults but it was different from all other discovered strains of Coronaviridae. Symptoms caused by this strain were febrile seizures, severe cough, high temperature, and asthma exacerbation. HCoV-NL63 had caused disease, especially in children less than 6 years leading to 224 hospitalized cases per 1 lac population annually in Hong Kong [15]. For three years from 2006 to 2009, screening tests were conducted on the large scale in the UK for 4 different strains of human coronaviruses (HCoV-OC43, HCoV-229E, HCoV-HKU1, HCoV-NL63, and HCoV-OC43) obtained by analyzing diagnostic respiratory samples.
Some samples (approximately 11 to $41 \%$ ) containing coronaviruses were also positive for other viruses which also caused respiratory infections such as influenza and parainfluenza viruses. But symptoms caused by these viruses and coronavirus monoinfestations were quite similar [16].

In the year 2010-2015, four human coronaviruses strains such as HKU1, 229E, OC43, and NL63 were reported prevalent in province Guangzhou. Several positive $\mathrm{HCoV}$ cases were reported such as NL63 (14.97\%), OC43 (60.20\%), HKU1 (7.82\%) and 229E $(16.67 \%)$.The monthly distribution of $\mathrm{HCoV}$ proved that the coronavirus prevalently occurs in winter and notable differences are found among different species. The peakvalley distribution trend observed in the fiveyear distribution of human coronaviruses $(\mathrm{HCoV})$ revealed that the detection rates were lower in the years 2010, 2012, and 2014, whereas higher in the years 2011 and 2013. The age distribution trend showed that there were two high-risk groups of $\mathrm{HCoV}$ including children age less than 3 years and older people above 50 years of age. It was observed that among the 294 positive $\mathrm{HCoV}$ patients, there were 101 cases $(34.69 \%)$ to be co-infected with many other respiratory diseases, and among these 30 cases $(29.70 \%)$ were co-infected mostly by the influenza virus. The two HCoV-OC43 genotypes such as genotype $\mathrm{B}$ and genotype $\mathrm{G}$ were first time revealed to be co-circulating and during the year 2013-2014, the genotype G was dominant and epidemic in Guanzhou province, South China [17].

A severe respiratory disorder, named MERS$\mathrm{CoV}$ in 2012 was known to have emerged in the Middle East patient who lived in Saudi Arabia.MERS CoV was responsible for $\geq 250$ human infections and 93 deaths [11]. The major cases have so far been declared in countries like Qatar, Jordan, Saudi Arabia, and U.A.E. The MERS-CoV and other associated viral species were included in the 
Betacoronavirus clade $\mathrm{C}$ genus and originated from the insectivorous bats in Africa and Europe. The Sero-epidemiology studies conducted on diverse species of livestock revealed the antibody response in dromedary camels against 5-8 MERS CoV antigens in countries; Oman, Saudi Arabia Jordan, United Arab States, Egypt, and Spain. The dromedary camels in Saudi Arabia, Qatar, and Egypt are considered to be the main animal reservoirs for zoonotic viral infections due to the close similarity between human MERS CoV and camel MERS CoV [18].

Various unknown pneumonia cases of unknown causes were declared in the Wuhan, located in province Hubei, China atthe start of December 2019. The deep sequencing of thepatient's sample from the respiratory tract by Chinese facilities discovered a new coronavirus as a causative organism named2019-nCoV (SARS-CoV-2) on $7^{\text {th }}$ Jan 2020. SARS-CoV-2 hasa strong ability to cause human infections by affecting the epithelial cells of respiratory tracts mainly through binding between angiotensin I converting enzyme 2(ACE2)receptor and viral spike protein in human cells.

The exposure to the humanwholesale seafood market, the trade site of wild animals in Wuhan, is considered to be epidemiologically linked to SARS-CoV-2 pathogen causing the majority of initial COVID-19 cases. To control the further spread of the coronavirus outbreak, the markets were closed down since $1^{\text {st Jan } 2020 .}$ The patients with travel history to Wuhan but no exposure to the market as well as those having direct physical contact with coronavirus patients had been confirmed positive for COVID-19. Most of the confirmed cases identified were health care workers representing a strong human-human transmission. Since $15^{\text {th }} \mathrm{Feb} 2020$, the pneumonia COVID-19 cases increased very rapidly up to 60,000 in China and the whole world. A mortality rateof approximately $2 \%$ was reported in countries with their relevant death cases such as Thailand(6), Japan(7), South Korea(8), and the USA(1524) respectively [19]. The overallcase fatality rate $(C F R)$ observed was $2.3 \%$ including 44672 cases and 1023 deaths. The CFR varies among different aged groups such as CFR in a population aged between 70 and 79 years was $8 \%$ and no death was reported in 9 years old children. The CFR (14.8\%) had occurred in patients $\geq 80$ years with almost no deaths among severe and mild cases. The CFR in the most critical cases was $49 \%$. The previously occurred comorbid medical conditionslike diabetes(7.3\%), cancer(5.6\%), acute respiratory disease $(6.3 \%)$, and myocardial infarction $(10.5 \%)$ were shown to elevate the human coronavirus CFR. A total of 44,672 cases were reported among which $3.8 \%$ (1716) were health care workers, $63 \%$ (1080) cases of them were observed in Wuhan. Among healthcare workers, 14.85\% were confirmed positive $\mathrm{HCoV}$ cases that considered either critical or severe with only 5 deaths reported. COVID-19 got quickly spread from a small single city to the whole country within only 30 days. The sheer speed of rapidly increasing COVID-19 cases and geographical expansion surprised and rapidly overwhelmed the human health and public health services remarkably in Wuhan, Hubei Province in China [20].

At present, as of February 2021, the stats for the COVID-19 cases are as follows; United States of America (USA) hasthe highest number of confirmed 26.3 million cases with 442,000 deaths. Secondly, India has been confirmed with 10.8 million cases of COVID-19 with 10.4 million recovered patients and154,000 deaths reported. Brazil has reported 9.2 million with 8.18 million recoveries and 225,000 deaths. The United Kingdom has 3.82 millionnumbers of cases with 106,000 confirmed deaths. Russia has 3.8 million confirmed cases of the virus with 
3.26 million recovered and 72,029 deaths. In France, 3.2 million cases were reported and 76, 512 deaths. Spain reported 2.82 million cases and 59, 081 deaths. Italy stands with 2.55 million cases with 2.01 million recoveries and 88, 516 deaths. Germany has 2.32 million confirmed cases of COVID-19 reported with 1.94 million recovered patients and 57,160 deaths reported. In Turkey, 2.49 million cases confirmed cases are reported with 2.37 million recovered and 26,117 deaths reported. Iran has 1.42 million cases reported with 1.21 million patients recovered and57, 959 deathsreportedaccording to the world health organization's report. The (Fig. 1)compares the worldwide COVID-19 cases, recoveries, and deaths.

On $26^{\text {th }}$ February 2020, the SARS-CoV-2 (COVID-19) emerged in Pakistan with two confirmed coronavirus-positive patients who had returned from Iran. The number of cases was reported to have increased within a week in areas such as Rawalpindi and Islamabad. The fifth case was reported in women from Gilgit \&Baltistan, on $2^{\text {nd }}$ March 2020, who also traveled from Iran. The COVID cases were doubled from 28 to 31 in Balochistan and from 33 to 80 in Punjab by $19^{\text {th }}$ March 2020 (nih.org.pk). Till the $29^{\text {th }}$ of April, 2020, 14,885 confirmed cases were reported in Pakistan with 327 deaths. Till the $20^{\text {th }}$ of May, 2020 the total case count rose to 45,898 with 13,101 recoveries and 985 deaths. The present stats, till $10^{\text {th }}$ June 2020 is; the total cases reported are 113,702 with 36,308 recoveries and 2,255 deaths. As of now,in February 2021 Pakistan has reported 546,000 total cases of the Coronavirus infection out of 501,000 have recovered and 11,683 died. The (Table1) showed the distribution of COVID19 cases by region of residence in Pakistan. This data is taken from the website of the Pakistani Government to raise public awareness (www.covid.gov.pk).

\section{How do coronaviruses spread and develop} the disease?

Coronaviruses have been identified to have a zoonotic mode of transmission. They can spread from animals to humans and later the infected humans affect the fellow humans. The popular animal of Coronavirus origin is "Bat" [21]. In the case of viral spread among humans, almost all the outbreaks of Coronaviruses reported a similar manner of transmission. Be it MERS-CoV, SARS-CoV, or the novel SARS-CoV-2, almost all of them spread via respiratory secretions like sneezes and coughs. The viruses spread from the infected persons to healthy people if they come in close contact with each other. The ill ones can transfer the virus to the people they meet directly and the health care professionals taking care of them. Moreover, they may also shed viruses to the places they visit like hospital surface areas, etc.

As there are no potential medicines for curing the infections caused by Coronaviruses, therefore; people are advised to prevent it as much as possible. Social distancing has been proposed as one of the major preventive measures for the viral spread. Doctors and medical experts urge people to maintain a safe distance from other people, especially the symptomatic ones, during the outbreaks. With respect to the development of infection or disease, coronaviruses damage the working of the immune system to a much greater extent. They are most likely to infect your respiratory system first, damaging the respiratory airways and leading to various respiratory syndromes. They also promote a variety of immune changes which may incapacitate the patients to fight the virus.

For instance, lymphocytes mainly Tlymphocytes like CD4+ \& CD8+ rapidly reduce during the acute phase of SARS-CoV infection. IgG antibodies specific to SARS are likely to be produced in the late stages of the acute phase of the infection, around 2 weeks, and increase gradually. However, the 
pathogenesis of SARS-CoV is much more complex. It causes severe damages to most of the vital organs in the human body as well [22].

At first, SARS-CoV was considered the most pathogenic among the coronaviruses, however; MERS-CoV reported more pathogenicity after it was discovered. It caused a much higher number of deaths than SARS-CoV and exhibited greater tissue tropism [23]. Moreover, immune changes associated with MERS-CoV are reported as follows; suppressed production of interferons, induction of pro-inflammatory cytokines, attenuation of innate immunity, and delaying of pro-inflammatory responses. In the case of MERS-CoV infection, the infected macrophages of the immune system significantly support the development of the disease [24]. Infiltration of immune cells occurs in the lower respiratory tract which causes damage to the respiratory tissues. This is one of the probable reasons that patients suffering from MERS develop progressive pneumonia. Other clinical manifestations include septic shocks, multi-organ damage (Table 2 enumerates the organ damage caused by SARS-CoV), acute respiratory distress syndrome, etc. The induction of proinflammatory cytokines and chemokines promotes respiratory dysfunction as well. Due to the availability of limited autopsies of the MERS-CoV infected patients, the accurate pathogenesis of the virus is difficult to explain. However, a significant number of in vitro studies report that the replication of the virus in the macrophages is the prominent cause of such extreme cytotoxicity [25].

SARS-CoV-2, like other coronaviruses, targets the respiratory system mainly. The main events related to the pathogenicity of the virus include RNAaemia, severe pneumonia, acute cardiac injury, etc. The virus elevates the levels of cytokines and chemokines in the blood [26]. The severe cases of COVID-19 infection have reported high levels of pro-inflammatory cytokines which adds to the severity of the disease. This is still an ongoing topic. Many scientists are presenting hypothesized pathogenesis for SARS-CoV-2 [27]. The major data demonstrate compromised working of the respiratory system and decreased immunity as major clinical manifestations for COVID19.

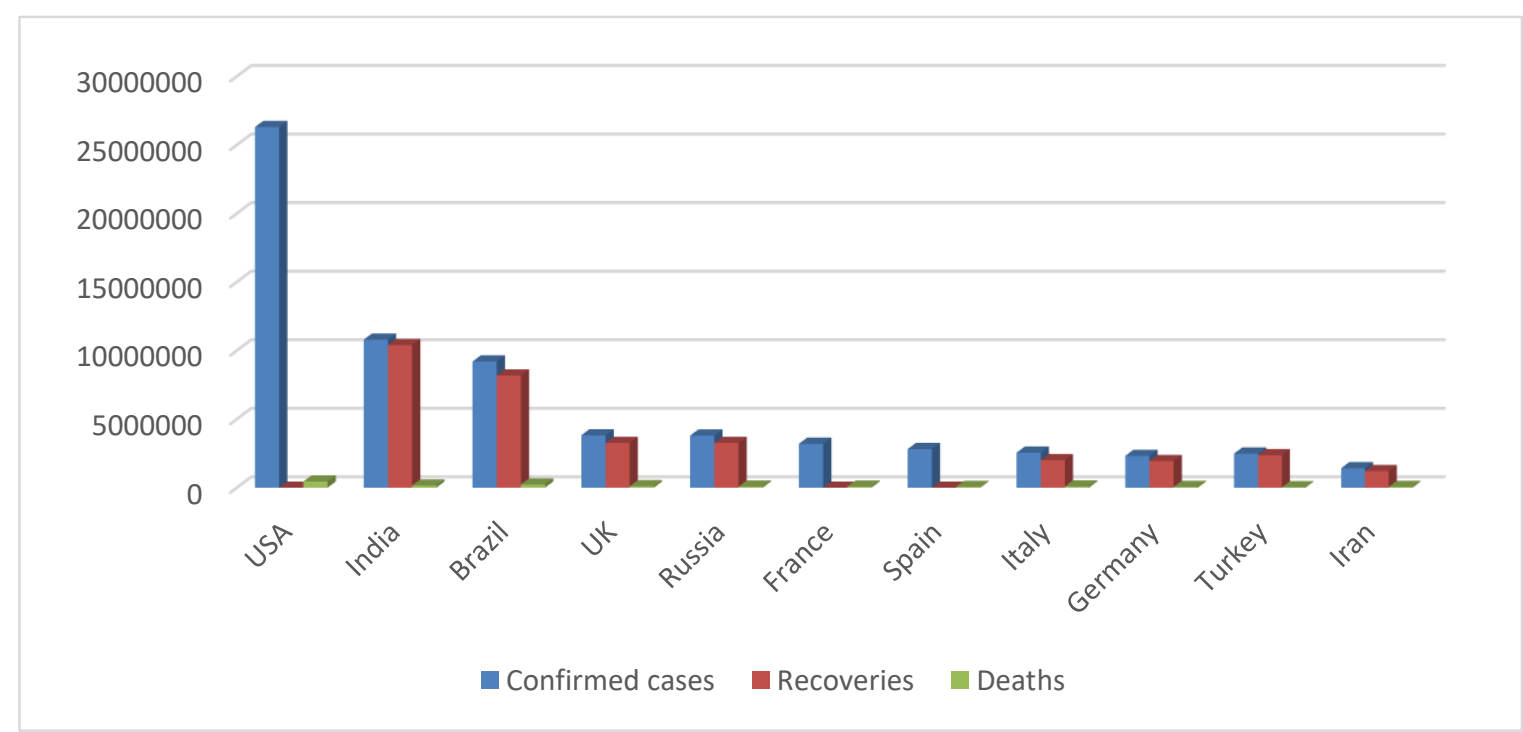

Figure 1. Comparison of worldwide cases, recoveries, and deaths from coronavirus pandemic 
Table 1. Distribution of COVID19 cases by region of residence in Pakistan

\begin{tabular}{|c|c|c|c|}
\hline Regions & Confirmed cases & Deaths reported & Recovered patients \\
\hline Sindh & 247,000 & 3,996 & 225,000 \\
\hline Punjab & 158,000 & 4,747 & 143,000 \\
\hline KPK & 67,214 & 1,906 & 62,385 \\
\hline Balochistan & 18,823 & 195 & 18,479 \\
\hline Islamabad & 41,418 & 475 & 39,562 \\
\hline $\boldsymbol{A J K}$ & 9,019 & 262 & 8,386 \\
\hline $\boldsymbol{G B}$ & 4909 & 102 & 4,787 \\
\hline
\end{tabular}

Table 2. Organ damage caused by SARS-CoV

\begin{tabular}{|c|c|}
\hline Lungs & $\begin{array}{c}\text { Intense damage to the alveoli, edema, cellular infiltration, vascular damage, } \\
\text { unusual pneumocytes }\end{array}$ \\
\hline Spleen & $\begin{array}{c}\text { Depletion of lymphocytes and white pulp atrophy along with the disruption of } \\
\text { lymph nodes }\end{array}$ \\
\hline $\begin{array}{c}\text { Kidneys } \\
\text { and Heart }\end{array}$ & $\begin{array}{c}\text { Necrosis in the tubular part of Kidneys } \\
\text { Mycordial atrophy and edema }\end{array}$ \\
\hline Neurons & Neural degeneration followed by edema \\
\hline Glands & $\begin{array}{c}\text { Infiltration of immune cells in the adrenal gland followed by its necrosis. } \\
\text { Destruction of follicular epithelium in the thyroid gland and various apoptotic } \\
\text { cells }\end{array}$ \\
\hline
\end{tabular}

\section{Symptoms}

The symptoms of SARS generally include fever, dyspnoea, lymphopenia, and quickly advancing changes in radiography. Upperrespiratory-tract side effects are not conspicuous, but loose bowels were reported by a few patients [28]. The sickness, as a rule, started with severe fever and mellow breathing problems but quickly altered to pneumonia in a fewdays [29]. SARS incorporates a characteristic clinical course for patients showing flu-like symptoms counting fever, chills, cough, discomfort, and dynamic breath shortness related to breathing problems [30, 31].

MERS-CoV is a modern viral plague, \& the contamination is related to severe lung sickness and kidney damage [32]. The foremost common appearances of sickness were muscle torment, fever, migraine, and dry hacks alongside breathing difficulties [33]. The analytical range of MERS-CoV disease ranges from having no symptoms (asymptomatic) or gentle lung disappointment to extreme intense lung infections\& death. An ordinary introduction of the MERS-CoV malady is an illness, coughing, and also breathing difficulties. Pneumonia may be an early finding as well. Gastrointestinal disappointments, counting the runs, have been also detailed.Serious sickness can result in lung disappointments that need a ventilation system and back in seriously care units. The infection shows up to result in more serious infections in more seasoned individuals, individuals with debilitated safe frameworks, and those people with persistent infections such as kidney problems,tumors, persistent lung illness, and diabetic problems. Patients contaminated with MERS-coronavirus endure pneumonia, taken after by ARDS and renal disappointment [34]. Some individuals having infection have no symptoms. When the infection does show symptoms, common ones incorporate low-grade fever, body throbs, coughing, nasal blockage, runny nose, and sore throat. 
In any case, COVID-19 can cause more extreme indications like tall fever, extreme hack \&frequently show pneumonia. One of the side effects of COVID-19 is shortness of breath. Signs and indications of SARS-CoV2 initiated COVID-19 are merely comparable to flu and regular sensitivities (dust hypersensitivities). Individuals enduring flu or regular sensitivity may too show a rise in temperature [35].

\section{Diagnosis}

A rapid diagnostic system is essential for the detection of infectious agents to recommend the treatment, stop the epidemic, and bring down the use of nonspecific antiviral drugs [36]. For the rapid identification of respiratory viral infection, Real-time reverse transcription PCR(RT-PCR), reverse transcription loop mediated-isothermal amplification PCR (RT-LAMP), Reverse transcription PCR, multiplex nucleic acid amplification, and microarray-based assays are highly recommended. These techniques can also be used in the detection and diagnosis of this novel coronavirus so-called SARS-CoV-2 [37]. The efficacy of these methods in the detection of COVID-19 is promising not only in humans but can also be attributed to the determination of the origin and intermediate host of the novel coronavirus. A pan corona assay may also be suggested for amplicon sequencing for viral infections' confirmation and characterization in case of negative reports of the putative pathogen from pneumonia outbreak [38]. The conserved spike 2 gene of SARS-CoV and MERS-CoV may also be suggested to be targeted by the primer and probe-based duplex RT-PCR [39]. Although therange of the easily available diagnostic methods forCOVID-19 is narrow as compared to other respiratory viral infections, yet recent researchhighlighted the real-time RT-PCR, Next-generation sequencing (NGS), electron microscopy as well ascell culture as detection methods for COVID-19.In clinical virology laboratories, Nucleic acid amplification test (NAAT) tests can be used for the detection of pathogenic organisms in respiratory infections [40]. Rapid detection methods can block thepotential transmission of infectious diseases. The disease suspected patients declared by the CT diagnosis of viral pneumonia requires urgentmedical treatment because it is considered as a medical emergencyso that the patient may not become a source of further transmission of the diseaseespeciallywhen there is a shortage of diagnostic kits. However, the limitations of CT still exist in the identification of specific viruses. To minimize this limitation, it is a crucial step for the radiologists to detect the overlapping of the CTresults of the COVID19 with CT results of disease caused by other viruses [40].

\section{Treatment}

Just like SARS and MERS-CoV, there is no particular drug available against the novel SARS-CoV-2. Usually, the best and the quick strategy against coronaviruses have been considering already available drugsto cope with the novel diseases caused by the virus. Several anti-viral drugs have already been used against SARS-CoV and MERS$\mathrm{CoV}$. These drugs included corticosteroids, interferon, ribavirin, lopinavir-ritonavir, and several others. Although none of the drugs is clinically proven. There are several drugs that are FDA proven and can be trialed against COVID-19. Among them are penciclovir, nafamostat, nitazoxanide [41]. The neuraminidase inhibitors including zanamivir and oseltamivir can also be the option against COVID-19 as they are effective against most seasonal influenza [42]. Combinations of different drugs have also been used for the treatment of different viral diseases. It is seen that viral load can be reduced by the combination of RitonavirandLopinavir with ribavirin [43]. Several virus-based and host-based therapies are there which can be proven beneficial 
against viral attacks. These virus-based therapies include anti-viral peptides and monoclonal antibodies which can target enzymes, spikes made of glycoproteins, accessory, and structural proteins and nucleic acid of the coronavirus. As far as host-based therapies are concerned, it involves the interruption in the host signaling pathway for the replication of the virus and increases interferon response [44]. A broad-spectrum drug named Remdesivir (RDV) or GS-5734, can inhibit the activity of RNA replicase or RdRp in MERS-COVand can be considered against SARS-2 [45]. It has also been reported that Remdesivir can inhibit murine hepatitis virus (MHV) and can interfere with viral polymerase and affects the activity of exoribonuclease activity of virus which has the proofreading ability [46]. Interferons like IFN $\alpha$ and IFN $\beta$ with the combination of other antiviral drugs are also under clinical trials [47]. Another drug named chloroquine has been used against malaria. Viral infection can be stopped by this drug as it results in the rise in the $\mathrm{pH}$ of endosomes and is also involved in the glycosylation of the SARS-CoV receptors. Due to the successful history of thisrespective medicine, researchers are also suggesting it treat SARS-2 [41]. There are many hurdles in producing anti-viral drugs against novel viruses. The model animals which can be used for the clinical trials of the drugs are not enough [44]. To inhibit bacterial and fungal attacks, a single antibiotic or a combination of different antibiotics are given to the patients. These include tigecycline, cephalosporins, quinolones, and carbapenems. Furthermore, methylprednisolone, methylprednisolone sodium succinate, and dexamethasone were also used for the treatment [48].

\section{Vaccination}

The development of a vaccine against such a tiny yet super creature is not an easy task. Many strategies are available for vaccine development like a viral base vaccine, DNA based vaccine, live-attenuated or inactivated vaccine, recombinant protein-based vaccine, and sub-unit vaccine [49]. Many pharmaceuticals are paying attention to plant models for the development of vaccines against COVID-19 as they are cost-effective and efficient [50].

After the emergence of SARS-2, vaccination production by fifteen different companies had been in progress. These include Inovio Pharmaceuticals, Moderna Therapeutics, Novavax, Johnson \& Johnson, and others. They had been using the combination of already available techniques and modern technology to produce an effective vaccine. For instance, scientists are using SUMMIT, a supercomputer by IBM, to target viral spike protein $S$ (a glycoprotein) or interface of viral S-protein and human receptor ACE-2 [51]. Atleast one year was required for the clinical trial phase- 1 of these vaccines and few of them have started with the human trials [52].

\section{Conclusion}

Belonging to the order Nidovirales and family Coronaviridae, coronaviruses are nonsegmented, positive-sense RNA viruses that infect upper or lower respiratory tracts in humans and other mammals. SARS-CoV with a $4 \%$ fatality rate and MERS-CoV with $37 \%$ CFR (case fatality rate) was first originated in 2002 and 2013 in China and Saudi Arabia respectively. Other strains like Human coronavirus-NL63, Human coronavirus-HKU, strain 229E and OC43 were also reported to cause infections in the human respiratory tract. In the late 1960s two strains, 229E, and OC43 were prevalent. Mostly these strains have carnivores as their intermediate hosts as well as reservoirs. $\mathrm{HCoV}$ mostly occurs in winters and suspected individuals are kids under 5 years and people over 50 years. Symptoms of coronaviruses range from asymptomatic infections to low-grade fever, chills, dry cough, flu, discomfort breathing pattern, sore throat, and high fever with severe 
pneumonia. They also include gastrointestinal and renal problems. Coronavirus at present is a threat to global health. Till April 16, 2020, there were $1,991,562$ cases of corona pandemic with 130,885 deaths across the world. The U.S.hasthe highest number of cases with 447,000 deaths. At present, 10300000 confirmed cases have been reported across the world. Reverse transcription loopmediated isothermal amplification PCR (RTLAMP), Real-time reverse transcription PCR (RT-PCR), multiplex nucleic acid amplification test (NAAT), and pan coronavirus assay are highly recommended for the diagnosis of illnesses caused by coronaviruses. Conserved spike genes of MERS-CoV and SARS-CoV are used as the target in developing and designing probes. Although no drug is clinically proven, several anti-virals such as corticosteroids, interferon, and ribavirin were still found effective against SARS and MERS. Several FDAproven drugs such as penciclovir, nafamostat, nitazoxanide are under trials against COVID19. Remdesivir (RDV) a broad-spectrum drug that inhibits RNA polymerase and Chloroquine the anti-malarial drug are reported effective against SARS-CoV-2. Several anti-bacterial and anti-fungals are given to prevent secondary infections. Currently, some pharmaceutical companies such as Inovio Pharmaceuticals, Moderna Therapeutics, Novavax, Johnson \& Johnson are trying to develop a potent vaccine after the outbreak of COVID-19. Many vaccines have entered human trials as well. A large number of vaccines have been sent to different areas of the world including Pakistan and scientists are hoping for their effective results.

\section{Authors' contributions}

Conceived and designed the experiments: $\mathrm{M}$ Idrees, S Rafique \& S Afzal, Performed the experiments: I Amin, M Shahid \& M Rani, Analyzed the data: M Hassan, B Ahmed \&
SRH Shah, Contributed materials/ analysis/ tools: M Farooq, A Iftikhar \& I Mir, Wrote the paper: M Rani, S Aamir \& M Shahid.

\section{References}

1. Huang C, Wang Y, Li X, Ren L, Zhao J, Hu Y\& Cao B (2020). Clinical features of patients infected with 2019 novel coronavirus in Wuhan, China. The lancet 395(10223): 497-506.

2. Li G, Fan Y, Lai Y, Han T, Li Z, Zhou P \& Wu J (2020). Coronavirus infections and immune responses. $J$ Med Virol 92(4): 424-432.

3. Kahn JS, \& McIntosh K (2005). History and recent advances in coronavirus discovery. The Pediatr Infect Dis J 24(11): S223-S227.

4. Fehr AR \& Perlman S (2015). Coronaviruses: an overview of their replication and pathogenesis. Coronaviruses 1-23.

5. Woo PC, Huang Y, Lau SK, \& Yuen KY (2010). Coronavirus genomics and bioinformatics analysis. Viruses 2(8): 1804-1820.

6. Neuman BW, Kiss G, Kunding AH, Bhella D, Baksh MF, Connelly S \& Buchmeier MJ (2011). A structural analysis of $\mathrm{M}$ protein in coronavirus assembly and morphology. J Struct Biol 174(1): 11-22.

7. Weiss SR \& Navas-Martin S (2005). Coronavirus pathogenesis and the emerging pathogen severe acute respiratory syndrome coronavirus. Microbiol Mol Biol Rev 69(4): 635-664.

8. Brian DA, Hogue BG \& Kienzle TE (1995). The coronavirus hemagglutinin esterase glycoprotein. In The coronaviridae. Springer, Boston, MA. pp. 165-179.

9. Vabret A, Mourez T, Dina J, Van Der Hoek L, Gouarin S, Petitjean J \&Freymuth F (2005). Human coronavirus NL63, France. Emerg Infect Dis 11(8): 1225. 
10. Ksiazek TG, Erdman D, Goldsmith CS, Zaki SR, Peret T, Emery S \& SARS Working Group (2003). A novel coronavirus associated with severe acute respiratory syndrome. New Engl J Med 348(20): 1953-1966.

11. Reusken CB, Haagmans BL, Müller MA, Gutierrez C, Godek GJ, Meyer B \& Koopmans MP (2013). Middle East respiratory syndrome coronavirus neutralising serum antibodies in dromedary camels: a comparative serological study.Lancet Infect Dis 13(10): 859-866.

12. Birch CJ, Clothier HJ, Seccull A, Tran T, Catton MC, Lambert SB, \&Druce JD (2005). Human coronavirus OC43 causes influenza-like illness in residents and staff of aged-care facilities in Melbourne, Australia. Epidemiol. Infect 133(2): 273277.

13. Fouchier RA, Hartwig NG, Bestebroer TM, Niemeyer B, De Jong JC, Simon JH \&Osterhaus AD (2004). A previously undescribed coronavirus associated with respiratory disease in humans. Proc Natl Acad Sci USA 101(16): 6212-6216.

14. Van Der Hoek L, Pyrc K, Jebbink MF, Vermeulen-Oost W, Berkhout RJ, Wolthers KC \& Berkhout B (2004). Identification of a new human coronavirus. Nat Med 10(4): 368-373.

15. Chiu SS, Hung Chan K, Wing Chu K, Kwan SW, Guan Y, Man Poon LL \& Peiris JS (2005). Human coronavirus NL63 infection and other coronavirus infections in children hospitalized with acute respiratory disease in Hong Kong, China. Clin Infect Dis 40(12): 1721-1729.

16. Gaunt ER, Hardie A, ClaasEC, Simmonds P \& Templeton KE (2010). Epidemiology and clinical presentations of the four human coronaviruses 229E, HKU1, NL63, and OC43 detected over 3 years using a novel multiplex real-time
PCR method. J Clin Microbiol 48(8): 2940-2947.

17. Zhang SF, Tuo JL, Huang XB, Zhu X, Zhang DM, Zhou K \& Xu L (2018). Epidemiology characteristics of human coronaviruses in patients with respiratory infection symptoms and phylogenetic analysis of HCoV-OC43 during 20102015 in Guangzhou. PloS One 13(1): e0191789.

18. Corman VM, Jores J, Meyer B, Younan M, Liljander A, Said MY \& Müller MA (2014). Antibodies against MERS coronavirus in dromedary camels, Kenya, 1992-2013. Emerg Infect Dis 20(8): 1319.

19. Shi H, Han X, Jiang N, Cao Y, Alwalid O, Gu J \& Zheng C (2020). Radiological findings from 81 patients with COVID19 pneumonia in Wuhan, China: a descriptive study. Lancet Infect Dis 20(4): 425-434.

20. Wu Z \& Mc-Googan JM (2020). Characteristics of and important lessons from the coronavirus disease 2019 (COVID-19) outbreak in China: summary of a report of 72314 cases from the Chinese Center for Disease Control and Prevention. Jama 323(13): 12391242.

21. Ye ZW, Yuan S, Yuen KS, Fung SY, Chan CP \& Jin DY (2020). Zoonotic origins of human coronaviruses.Int J Biol Sci 16(10): 1686.

22. Gu J \& Korteweg C (2007). Pathology and pathogenesis of severe acute respiratory syndrome. Am $J$ Pathol 170(4): 1136-1147.

23. Zielecki F, Weber M, Eickmann M, Spiegelberg L, Zaki AM, Matrosovich M \& Weber F (2013). Human cell tropism and innate immune system interactions of human respiratory coronavirus EMC compared to those of severe acute respiratory syndrome coronavirus. $J$ Virol 87(9): 5300-5304. 
24. Zhou J, Chu H, Li C, Wong BH, Cheng ZS, Poon V \& Yuen KY (2014). Active replication of Middle East respiratory syndrome coronavirus and aberrant induction of inflammatory cytokines and chemokines in human macrophages: implications for pathogenesis. Int J Infect Dis 209(9): 1331-1342.

25. Choudhry H, Bakhrebah MA, Abdulaal WH, Zamzami MA, Baothman OA, Hassan MA \& Jamal MS (2019). Middle East respiratory syndrome: pathogenesis and therapeutic developments. Future Virol 14(4): 237-246.

26. Rothan HA \& Byrareddy SN (2020). The epidemiology and pathogenesis of coronavirus disease (COVID-19) outbreak. J Autoimmun 109: 102433.

27. Lin L, Lu L, Cao W \& Li T (2020). Hypothesis for potential pathogenesis of SARS-CoV-2 infection-a review of immune changes in patients with viral pneumonia. Emerg Microbes Infect 9(1): 727-732.

28. Collins AR (1998). Human macrophages are susceptible to coronavirus OC43. In Coronaviruses and Arteriviruses (pp. 635-639). Springer, Boston, MA.

29. Zhong NS, Zheng BJ, Li YM, Poon LL, Xie ZH, Chan KH \& Guan Y (2003). Epidemiology and cause of severe acute respiratory syndrome (SARS) in Guangdong, People's Republic of China, in February, 2003. The Lancet 362(9393): 1353-1358.

30. Donnelly CA, Ghani AC, Leung GM, Hedley AJ, Fraser C, Riley S \& Anderson RM (2003). Epidemiological determinants of spread of causal agent of severe acute respiratory syndrome in Hong Kong. The Lancet 361(9371): 1761-1766.

31. Dayer MR, Taleb-Gassabi S \& Dayer MS (2017). Lopinavir; a potent drug against coronavirus infection: insight from molecular docking study. Arch Clin Infect Dis 12(4).

32. Alghamdi IG, Hussain II, Almalki SS, Alghamdi MS, Alghamdi MM, \& ElSheemy MA (2014). The pattern of Middle East respiratory syndrome coronavirus in Saudi Arabia: a descriptive epidemiological analysis of data from the Saudi Ministry of Health. Int J Gen Med 7: 417.

33. Alraddadi BM, Al-Salmi HS, JacobsSlifka K, Slayton RB, Estivariz CF, Geller AI \& Madani TA (2016). Risk factors for Middle East respiratory syndrome coronavirus infection among healthcare personnel. Emerg Infect Dis 22(11): 1915.

34. Memish ZA, Zumla AI, Al-Hakeem RF, Al-Rabeeah AA \& Stephens GM (2013). Family cluster of Middle East respiratory syndrome coronavirus infections. $N$ Engl $J$ Med 368(26): 2487-2494.

35. Xia W, Shao J, Guo Y, Peng X, Li Z \& Hu D (2020). Clinical and CT features in pediatric patients with COVID-19 infection: different points from adults. Pediatr Pulmonol 55(5): 1169-1174.

36. Zhang N, Wang L, Deng X, Liang R, Su M, HeC \& Jiang S (2020). Recent advances in the detection of respiratory virus infection in humans. $\mathrm{J}$ Med Virol 92(4): 408-417.

37. Fahimi H, Allahyari H, Hassan ZM, \& Sadeghizadeh M (2014). Dengue virus type-3 envelope protein domain III; expression and immunogenicity. Iran J Basic Med Sci 17(11): 836.

38. Jiang S, Du L \& Shi Z (2020). An emerging coronavirus causing pneumonia outbreak in Wuhan, China: calling for developing therapeutic and prophylactic strategies. Emerg Microbes Infec 9(1): 275-277.

39. Noh JY, Yoon SW, Kim DJ, Lee MS, Kim JH, Na W \& Kim HK (2017). Simultaneous detection of severe acute 
respiratory syndrome, Middle East respiratory syndrome, and related bat coronaviruses by real-time reverse transcription PCR. Arch Virol 162(6): 1617-1623.

40. Phan T (2020). Novel coronavirus: From discovery to clinical diagnostics. Infect Genet Evol 79: 104211.

41. Wang M, Cao R, Zhang L, Yang X, Liu J, Xu M \& Xiao G (2020). Remdesivir and chloroquine effectively inhibit the recently emerged novel coronavirus (2019-nCoV) in vitro. Cell Res 30(3): 269-271.

42. Chan JF, Chan KH, Kao RY, To KK, Zheng BJ, Li CP \& Yuen KY (2013). Broad-spectrum antivirals for the emerging Middle East respiratory syndrome coronavirus. J Infect 67(6): 606-616.

43. Totura AL \&Bavari S (2019). Broadspectrum coronavirus antiviral drug discovery. Expert Opin Drug Deliv 14(4): 397-412.

44. Zumla A, Chan JF, Azhar EI, Hui DS \& Yuen KY (2016). Coronaviruses-drug discovery and therapeutic options. Nat Rev 15(5): 327-347.

45. Gordon CJ, Tchesnokov EP, Feng JY, Porter DP, \& Götte M (2020). The antiviral compound remdesivir potently inhibits RNA-dependent RNA polymerase from Middle East respiratory syndrome coronavirus. $J$ Biol Chem 295(15): 4773-4779.

46. Agostini ML, Andres EL, Sims AC, Graham RL, Sheahan TP, Lu X \& Denison MR (2018). Coronavirus susceptibility to the antiviral remdesivir (GS-5734) is mediated by the viral polymerase and the proofreading exoribonuclease. Mol Biol 9(2).

47. Cheng VC, Lau SK, Woo PC \& Yuen KY (2007). Severe acute respiratory syndrome coronavirus as an agent of emerging and reemerging infection.Clin Microbiol Rev, 20(4), 660-694.

48. Chen N, Zhou M, Dong X, Qu J, Gong F, Han Y \& Zhang L (2020). Epidemiological and clinical characteristics of 99 cases of 2019 novel coronavirus pneumonia in Wuhan, China: a descriptive study. The Lancet 395(10223): 507-513.

49. Chen Y, Liu Q \& Guo D (2020). Emerging coronaviruses: genome structure, replication, and pathogenesis. $J$ Med Virol 92(4): 418-423.

50. Shanmugaraj B, Malla A, \& Phoolcharoen W (2020). Emergence of novel coronavirus 2019-nCoV: need for rapid vaccine and biologics development. Pathogens 9(2): 148.

51. Smith MD \& Smith JC (2019). Repurposing Therapeutics for COVID19: Supercomputer-Based Docking to theSARS-CoV-2 Viral Spike Protein and Viral Spike Protein-Human ACE2 Interface.

52. Pang J, Wang MX, Ang IY, Tan SH, Lewis RF, Chen JI \& Hsu LY (2020). Potential rapid diagnostics, vaccine and therapeutics for 2019 novel coronavirus (2019-nCoV): a systematic review. J Clin Med 9(3): 623. 